\title{
The perception of time relations in auditory tempo discrimination
}

\author{
STEWART H. HULSE and CURTIS L. KLINE \\ The Johns Hopkins University, Baltimore, Maryland
}

\begin{abstract}
European starlings (Sturnus vulgaris) were trained to discriminate between pulses of sound presented at rates (tempos), for different birds, of $4 / \mathrm{sec}$ and $8 / \mathrm{sec}$ or $8 / \mathrm{sec}$ and $16 / \mathrm{sec}$ in a twoalternative choice task. Once the discrimination was learned, psychometric functions and bisection points were determined for tempos between the standards. Then the starlings were transferred to a new discrimination, which either maintained or changed the relationship between response keys and tempo (relational or nonrelational transfer). The results showed that the starlings generated psychometric functions for tempo with properties much like those found for discrimination of single time intervals. Also, the starlings transferred the tempo discrimination faster under the relational than the nonrelational condition. In general, starlings-like human and other nonhuman animals-perceive temporal structures as invariant over proportional changes in the duration of structural elements.
\end{abstract}

Timing by nonhuman animals has been a subject of vigorous study both empirically and theoretically (e.g., Church, 1978; Church \& Broadbent, 1990; Dreyfus, Fetterman, Smith, \& Stubbs, 1988; Fetterman \& Dreyfus, 1987; Fetterman \& Killeen, in press; Gibbon, 1977, 1986; Gibbon \& Allan, 1984; Gibbon \& Church, 1990). In almost all cases, however, interest has focused on the mechanisms that organisms use to time (or make other temporal judgments about) a single interval that begins at some moment, $t_{0}$, and ends at some later moment, $t_{1}$. With just two exceptions that we are aware of (Hulse, Humpal, \& Cynx, 1984; Meck, Church, \& Olton, 1984), there has been no work with animal subjects on the processes that might be involved in perceiving time intervals that are expressed repetitively. On the other hand, much research has been done with human subjects on the perception of repetitive sound patterns. For example, many experiments have examined rhythm perception in the realm of human music perception (e.g., Deutsch, 1982; Fraisse, 1964, 1978; Povel \& Essens, 1985).

In the first of the two studies that have been done with animals, Meck et al. (1984) primarily addressed the role of hippocampal function in timing. They trained rats to discriminate between signals that varied in both total duration $(2$ or $8 \mathrm{sec})$ and the rate at which a component stimulus within the two signal durations repeated $(2 / \mathrm{sec}$ or $16 / \mathrm{sec})$. They found that rats could readily discriminate on the basis of either signal duration or stimulus rate. A bisection procedure generated a standard psychophysical function for

We thank Richard Braaten, Daniel Bernard, Cynthia Gray, Suzanne Page, and Annie Takeuchi for many helpful comments about the manuscript. The research reported in this paper was supported by National Science Foundation Grant BNS-891 1046. Correspondence concerning this article should be addressed to S. H. Hulse, Department of Psychology, Johns Hopkins University, Baltimore, MD 21218 (e-mail: hulse@jhuvm.bitnet). both duration and rate, with bisection points close to the geometric mean in each case. These results agree with predictions from scalar timing theories (e.g., Gibbon, 1977; Gibbon \& Allan, 1984; Gibbon \& Church, 1990).

In the other animal study, Hulse, Humpal, and Cynx (1984) showed that European starlings (Sturnus vulgaris) could discriminate one repeating series of tones that varied randomly in duration from another repeating series of tones that were fixed in duration. Most significantly, the starlings maintained the discrimination when the random and fixed series were either slowed or speeded in rate; that is, when the series were changed in the tempo with which they were played. This suggests that the birds were perceiving the patterns on a relational basis. They were, in other words, perceiving the random or fixed temporal structure of the patterns on a basis independent of the actual tone durations used to construct the patterns.

Experiments in which animals have discriminated between two single time intervals of different durations also suggest the possibility that animals perceive repeating temporal structures on a relational basis (e.g., Church \& Deluty, 1977; Fetterman, 1987; Fetterman, Stubbs, \& Dreyfus, 1986). The available evidence indicates that animals (rats and pigeons) are in fact quite consistent in responding to such interval comparisons relationally. That is, the animals code the comparisons on a "longer" or "shorter" basis-a basis that generalizes to discriminations between many absolute durations of the intervals involved.

In this paper, we report additional information on animals' ability to process repeating patterns of tones that vary in rate (tempo). We replicated with starlings the psychometric function for the bisection of two tempos obtained by Meck et al. (1984) for rats. We also report the results of a new transfer test designed to explore further the possibility that starlings process tempo structures on a relational basis. 


\section{BASELINE DISCRIMINATION}

\section{Method}

Subjects. Nine experimentally naive, adult male wild-caught European starlings (Sturnus vulgaris) of unknown age served as subjects. They were obtained from the Patuxent Federal Wildlife Preserve in Laurel, MD. The starlings were maintained at $85 \%-90 \%$ of their free-feeding weights on a diet consisting of Purina Start-N-Grow (Ralston-Purina, St. Louis, MO). For reinforcement in the test apparatus, this diet was combined with ground hard-boiled eggs (shells included), ground carrots, and moist dog food. Grit and water were available in the home cages, and water was available in the test chamber. The birds were housed in individual cages in an aviary with approximately 50 other starlings. The light:dark cycle in the aviary was controlled by a Paragon (Two Rivers, W) Model EC72ST Sun Tracker timer, and was set to match the day:night cycle in Baltimore, MD.

Apparatus. The starlings were tested in a wire-mesh cage, $28 \mathrm{~cm}$ wide $\times 20 \mathrm{~cm}$ high $\times 30 \mathrm{~cm}$ deep, which was suspended in the center of an $80 \times 60 \times 60 \mathrm{~cm}$ sound-attenuating chamber (Model AC3, Industrial Acoustics Company, New York, NY). Three translucent keys, $2 \mathrm{~cm}$ in diameter, were located $4 \mathrm{~cm}$ apart on a panel facing the bird. Two rectangular holes $(6.0 \mathrm{~cm}$ wide $\times 4.5 \mathrm{~cm}$ high), located $4.5 \mathrm{~cm}$ beneath the side keys and $2 \mathrm{~cm}$ above the floor of the cage, allowed access to food hoppers (Model G5610, Gerbrands, Cambridge, MA) when the hoppers were in the raised position. Two 28-V (No. 1820) light bulbs, mounted behind a translucent screen on the center of the back wall of the chamber, provided a houselight. A Jensen (Lincolnshire, IL) 14-cm speaker was mounted $22 \mathrm{~cm}$ directly above the test cage.

Sound generation, experimental contingencies, and data recording were controlled by an IBM PC/AT-compatible microcomputer. For sound generation, the computer controlled a Data Translation (Marlborough, MA) Model 2801 digital-analog converter. The computer-generated sounds were passed through a Coulbourn Instruments (Lehigh Valley, PA) gate that was set for a linear 8-msec rise/fall time. Output from the gate went to a $10-\mathrm{kHz}$ lowpass filter and then to a Crown International (Elkhar, IN) Model D-75 amplifier. The amplifier output went to the speaker located in the chamber.

Stimuli. The stimuli consisted of repetitions of $10-\mathrm{msec}$ pulses of a $1000-\mathrm{Hz}$ sine tone generated in real time from a wave table in computer software. Pulses were measured at $65 \mathrm{~dB}$ SPL by a microphone placed at a location in the test chamber directly in front of the response keys. The pulses were combined with different intertone intervals to generate pulse streams of varying rates or tempos. For initial discrimination training, the pulses were separated by intertone intervals of either 240,115 , or $52 \mathrm{msec}$. These time relations produced pulse trains with tempos of 4.8 , or 16.129 pulses $/ \mathrm{sec}$. The latter tempo departed from a nominal $16 \mathrm{pulses} / \mathrm{sec}$ exactly, because of software timing constraints. The experiments provided no evidence that the starlings could discriminate tempos in the immediate region of 16 pulses/sec: therefore, this label will be used for the baseline tempo of $16.129 \mathrm{pulses} / \mathrm{sec}$.

To minimize initial speaker transients and to keep the apparatus compatible with other experiments running in the laboratory at the same time, the first pulse in a pulse train was initiated during a trial by the electronic gate. Subsequent pulses in a train were gated by software. The pulse trains continued for an amount of time that was determined by the experimental contingencies described below.

Sonograms determined from recordings made in the experimental chambers showed that the stimuli reaching the subjects' ears were richly harmonic, in spite of the fact that they were generated from sine tones. This was no doubt due to speaker characteristics and to resonances in the acoustic chambers. Most energy was in the fundamental range of $1000 \mathrm{~Hz}$; however, from pulse to pulse, amplitude levels over the second through the fourth harmonic were down to 5 to $10 \mathrm{~dB}$. Levels fell to approximately $20 \mathrm{~dB}$ with the fifth harmonic, and were scarcely measurable thereafter. Although the individual pulses varied somewhat in their spectra (again, most likely due to speaker characteristics), there was no evidence that the spectra varied in any systematic way from pulse to pulse within the pulse train for a given tempo, or for pulses from tempo to tempo. To the human ear, the individual pulses for all the tempos sounded like sharp, plucked "ticks," with little sense of pitch.

Five of the starlings heard stimuli that began with the pulse of sound, while the other 4 starlings heard stimuli that began with the intertone interval. These treatments were counterbalanced across conditions.

Procedure. The starlings were trained to eat from the food hoppers, and were then shaped to peck at the illuminated center key for access to the food hoppers. Next, the birds were shaped to peck first at the center key, then at an illuminated side key, with the right and left keys alternating from trial to trial. Correct pecks to the left key were always reinforced by access to the left food hopper, and correct pecks to the right key were reinforced by access to the right hopper.

Discrimination training then followed with a two-alternative choice (go right/go left) procedure. Daily sessions lasted $2.5 \mathrm{~h}$. Each trial within a session started with the illumination of the houselight, followed $10 \mathrm{sec}$ later by illumination of the center key. Pecks at the center key darkened the key, lit the side keys, and produced one of two stimulus patterns ( $p=.50$ ). Five birds were trained to discriminate between tempos of 4 and $8 \mathrm{pulses} / \mathrm{sec}$, while the other 4 birds were trained to discriminate between tempos of 8 and 16 pulses/sec. Within each tempo condition, a tempo was assigned to a unique side key, left or right. Thus, for the $4 / 8$ tempo condition, the 4-pulse/sec stimulus might be assigned to the left key, and the 8-pulse/sec stimulus to the right. Stimulus key assignment was counterbalanced across birds. Correct responses were reinforced with 3-sec access to the food hopper that was located beneath the appropriate key. A 5-sec intertrial interval (ITI) followed the 3-sec reward period. The ITI was followed by the start of the next trial. Pecks to the incorrect key during a trial darkened the key and turned off the houselight for a 10-sec time-out. The ITI then followed.

On all trials, stimulus pattems played until a side key was pecked, or for a variable length of time $(2.5-4 \mathrm{sec})$, whichever came first. If the bird did not respond within this period, the center key darkened and the ITI started. Incorrect responses and trials with no response were followed by correction trials, in which the same stimulus pattern was repeated. Data from the correction trials were not used in subsequent analyses.

After 30 days of training, the side keys were no longer lit following the peck to the center key that started a trial. This was done to emphasize sound pattern onset as a salient cue rather than an illuminated side key. One bird (L1) stopped pecking the side keys when they were darkened, so, for this bird, the keys were turned on for the first half of each session for the seven sessions that followed. The keylights were then darkened permanently, and the bird continued to respond.

\section{Results and Discussion}

All the starlings learned their respective discriminations, taking between 38 and 93 sessions to reach a criterion of $85 \%$ correct within a session.

When the starlings' performance was stable at criterion, as judged by inspection of the data, we undertook two experiments to study the properties of the basic discrimination. Each experiment lasted from 1 to 10 days and was followed by a return to the baseline discrimination until the starlings' performance restabilized. 


\section{EXPERIMENT 1 \\ Determination of a Psychometric Function for Tempo}

In this experiment, we determined psychometric functions for tempo by testing the birds with tempos other than the baseline tempos.

\section{Method}

Subjects and Apparatus. The subjects and apparatus were the same as those used in the baseline discrimination.

Stimuli. Ten new tempos were used as probe stimuli (see Table 1). Six had pulse rates between the training tempos; two were faster and two were slower than the training tempos. Except for the tempo changes, the stimuli were identical to those used in the baseline discrimination.

Procedure. For eight daily sessions, $10 \%$ of the trials were probe trials in which the birds were exposed to 1 of the 10 probe tempos. The remaining trials were standard baseline discrimination trials incorporating the 2 baseline tempos. Each probe tempo had an equal chance of occurring on probe trials $(p=.10)$. Responses to probe trials led immediately to the ITI, without reinforcement or time-out.

\section{Results and Discussion}

The starlings produced typical S-shaped psychometric functions. The data indicate that the starlings responded to tempo changes on a relational basis, described well by the principles underlying Weber's law.

Figure 1 displays psychometric functions for each bird. The proportions of responses to the "fast" key are plotted as a function of stimulus tempo. The functions are grouped by the tempos to which the birds were exposed. Although there was some variability among the birds, all functions within the $4 / 8$ and $8 / 16$ tempo conditions have the same general shape and slope.

Figure 2 displays mean proportions of responses on the "fast" key to probe stimuli for the starlings trained with the 4/8 and 8/16 discriminations and tested with the probe tempos appropriate for each. The tempos for the birds tested with the 4/8 stimuli were scaled for display in Figure 1 by doubling them. If Weber's law holds for tempo, the data for both the (scaled) 4/8 stimuli and the 8/16 stimuli should be fit by the same function; that is, the two functions should superimpose. Figure 2 shows that this was indeed the case.

Table 1

Tempos (Pulses per Second) Used as Bisection Probes in Experiment 1

Baseline Discrimination

\begin{tabular}{cc}
\multicolumn{2}{c}{ Baseline Discrimination } \\
\hline 4 vs. 8 Pulses/Sec & 8 vs. 16 Pulses/Sec \\
\hline 2.50 & 7.00 \\
3.00 & 7.70 \\
4.17 & 9.10 \\
5.00 & 10.00 \\
5.56 & 11.10 \\
6.00 & 12.50 \\
7.00 & 14.00 \\
7.70 & 15.00 \\
9.10 & 17.00 \\
10.00 & 19.00 \\
\hline
\end{tabular}

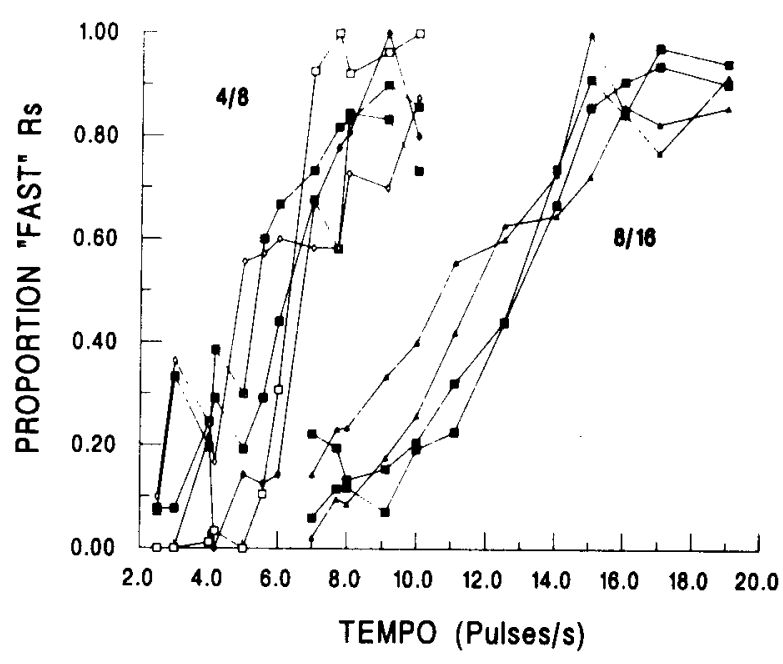

Figure 1. Proportions of pecks to "fast" key as a function of probe tempos (pulses per second) for individual starlings trained on 4versus 8-, and 8- versus 16-pulse/sec discriminations.

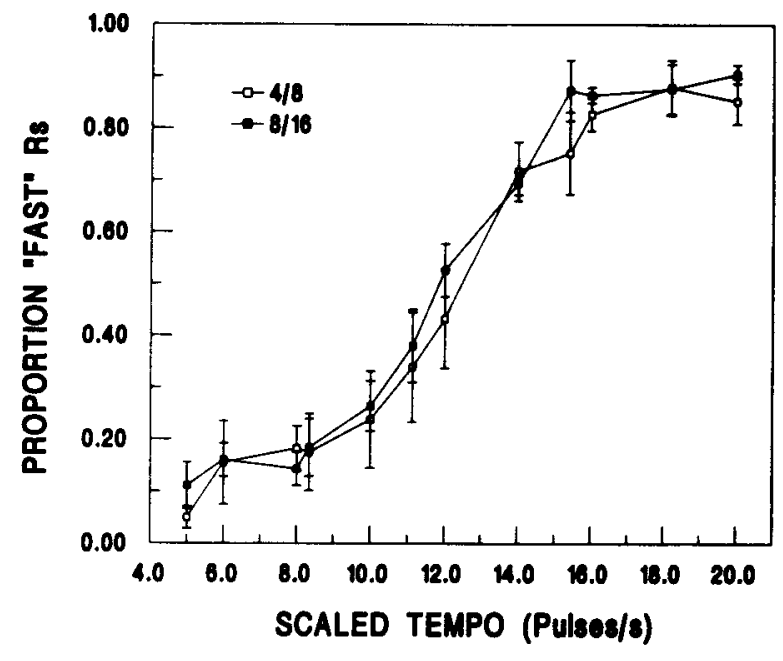

Figure 2. Proportions of pecks to "fast" key as a function of probe tempos (pulses per second) in the bisection procedure of Experiment 1. Data are from a group trained with 8- and 16-pulse/sec stimuli, and a group trained with 4 and 8-pulse/sec stimuli. Tempos for the latter have been scaled by doubling their values. Error bars are standard errors of the mean.

Bisection points for psychometric functions based on temporal data are often found at the geometric mean of the stimulus values involved (e.g., Church \& Deluty, 1977; Gibbon, 1986; Fetterman \& Killeen, in press). In order to determine whether this was so for data based on tempos as well, a bisection point for the data of Figure 2 was calculated as follows. Proportions for the tempos in the figure were transformed to normal deviates. Proportions for 8 and 16 pulses/sec were included, but values below and above these limits were not. Proportions for stimulus values common to the $4 / 8$ and $8 / 16$ conditions in the figure (e.g., the two values at 8 and $16 \mathrm{pulses} / \mathrm{sec}$ ) were averaged and normal deviates were calculated for 
the averages. The resulting scores were fit with a straight line by the method of least squares. This procedure produced a linear function with $r^{2}=.96$, and a bisection point at the 0 deviate value corresponding to a tempo of $11.88 \mathrm{pulses} / \mathrm{sec}$. For the tempos involved, the bisection point is closer to the arithmetic mean of 12.00 pulses/sec than it is to the geometric mean of $11.31 \mathrm{pulses} / \mathrm{sec}$.

The bisection point was calculated similarly, and for the unscaled $4 / 8$ data taken alone was 5.93 pulses/sec. This compares with an arithmetic mean of $6.00 \mathrm{pulses} / \mathrm{sec}$ and a geometric mean of 5.67 pulses/sec. For the 8/16 data taken alone, the bisection point was 11.63 pulses $/ \mathrm{sec}$. This compares with an arithmetic mean of 12.00 pulses $/ \mathrm{sec}$ and a geometric mean of 11.31 pulses/sec.

Taken together, only the bisection point for the $8 / 16$ data taken by themselves corresponded closely to the geometric mean-a correspondence characteristic of earlier data (e.g., Church \& Deluty, 1977). Zeiler (1985) noted that bisection points are not always at the geometric mean for temporal data, for reasons often related to experimental procedures.

It is worth noting parenthetically that the arithmetic, geometric, and harmonic means of the tempos correspond to the harmonic, geometric, and arithmetic mean of the intervals separating sounds in the pulse train defining a tempo. We discuss the data in terms of tempo, but the data could be expressed in terms of interpulse interval. For theoretical purposes, corresponding translations of the data with respect to the bisection point would then be in order.

Difference limens (Dls) were calculated for the $4 / 8$ and $8 / 16$ psychophysical functions by averaging the tempo values calculated for normal deviates at response proportions of .25 and .75 ; that is, the tempo values that the birds would have called "fast" $25 \%$ and $75 \%$ of the time. The Dls were then divided by the value for the bisection point in order to determine a Weber fraction. The Weber fraction for the $4 / 8$ function was .176 ; for the $8 / 16$ function it was .154 . Although not identical, these fractions are similar. They imply that Weber's law holds reasonably well over the ranges of tempos studied-a conclusion certainly supported by the good fit for the combined functions displayed in Figure 2. All this in turn implies that, in general, starlings perceive tempos relationally.

Although we conclude that the starlings were responding on the basis of time and tempo, it is conceivable that they were responding to other perceptual dimensions that may have been confounded with changes in pulse rate. One possibility is that the timbre, or tone quality of the sounds varied systematically with tempo. Although timbre is a nominal, qualitative dimension, perhaps the spectra associated with the tones of different tempos could nevertheless change, in some graded fashion, with tempo. Timbres can, for example, be arranged in multidimensionally determined similarity spaces, such that some timbres are "closer" in similarity than others (Grey, 1977; Grey \& Gordon, 1978). Our spectral measurements of the stimuli belie this possibility, however, because there were no systematic changes in the spectrum of the tones for tempos of different pulse rates.

Another possibility is that tone spectrum interacted in some fashion with tempo to produce a graded stimulus dimension, perhaps because the starlings' auditory systems failed to temporally segregate sounds over the range of intertone intervals that were used. This possibility is belied in general by the fact that the temporal resolving power of songbirds is much like that of mammals (Dooling, 1980). More important, starlings readily resolve temporal gaps as short as $3.2 \mathrm{msec}$ between bursts of broadband noise (Klump \& Maier, 1989). Our shortest interpulse intervals $(52 \mathrm{msec})$ were more than an order of magnitude larger. To be sure, our stimuli were nominally sine tones and not broadband noise, and were repeated in pulse trains. But there is no a priori reason to believe that these stimulus differences would change gap-detection thresholds sufficiently (if at all) to induce a graded qualitative change in the tones as a function of their tempo. The sum of the evidence leads to the conclusion that the starlings were using temporal aspects of the pulse trains to solve the tempo discrimination and to produce the psychometric functions.

\section{EXPERIMENT 2 Absolute Versus Relative Perception of Tempo}

The results of Experiment 1 showed that the starlings responded to probe tempos between or near the baseline tempos according to psychophysical principles, suggesting perceptual constancy for constant ratios among tempos. In Experiment 2, we provided another test of the relational processing of the pulse rates associated with different tempos. Transfers were designed to determine whether the birds were coding the baseline tempos with their associated responses absolutely (e.g., 4 pulses $/ \mathrm{sec} \rightarrow$ peck left, 8 pulses/sec $\rightarrow$ peck right), or relationally (e.g., slower tempo $\rightarrow$ peck left, faster tempo $\rightarrow$ peck right).

\section{Method}

Subjects and Apparatus. The subjects and apparatus were the same as those used in the baseline discrimination.

Stimuli. The stimuli consisted of pulse trains that were identical to the training stimuli. The tempos of the pulse trains for any given bird were 4 and 8 pulses/sec, or 8 and 16 pulses/sec, depending on which stimuli were used for initial training for any bird.

Procedure. The starlings that had been trained on stimuli of 4 and $8 \mathrm{pulses} / \mathrm{sec}$ were transferred to 8 and $16 \mathrm{pulses} / \mathrm{sec}$, and vice versa. Five of the starlings (Y3, L4, M15, G30, and P69) were tested in a relational transfer condition, in which the association between right and left keys and fast and slow tempos was the same as in the baseline discrimination, Of these, Y3 and P69 were transferred from $4 / 8$ stimuli to $8 / 16$ stimuli, and M15, L4, and G30 from $8 / 16$ to $4 / 8$ stimuli. For the other 4 starlings (L1, Y2, A33, and $\mathrm{Z76}$ ), the association between fast and slow tempos and keys was reversed in a nonrelational transfer condition. Of these, L1, A33, and $Z 76$ were transferred from $4 / 8$ to $8 / 16$ stimuli and $Y 2$ from $8 / 16$ to $4 / 8$ stimuli. Thus, as Figure 3 shows, if a starling had been trained to peck at the left key for 4 pulses/sec and the right key for $8 \mathrm{pulses} / \mathrm{sec}$, it was transferred to $8 \mathrm{pulses} / \mathrm{sec}$ on the left key 


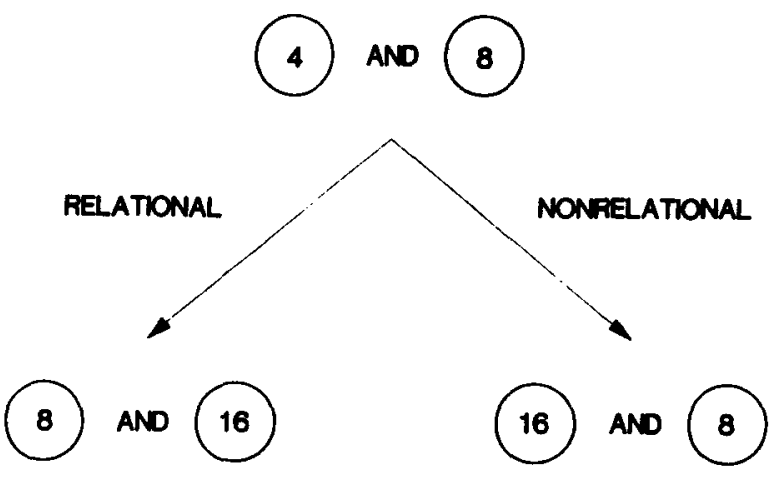

Figure 3. Transfer procedure for Experiment 2 for a starling originally trained to peck the left key for a tempo of 4 pulses/sec and the right key for 8 pulses/sec. In the relational transfer, the 8-pulse/ $\sec$ ("slow") stimulus was on the left and the 16-pulse/sec ("fast") stimulus was on the right. In the nonrelational transfer, the 16pulse/sec ("different") stimulus was on the left and the 8-pulse/sec ("same") stimulus was on the right.

and $16 \mathrm{pulses} / \mathrm{sec}$ on the right key (in the relational transfer) or $16 \mathrm{pulses} / \mathrm{sec}$ on the left key and $8 \mathrm{pulses} / \mathrm{sec}$ on the right key (in the nonrelational transfer).

Consider the starlings trained with the $4 / 8$ baseline discrimination, as in Figure 3. If they had used fast-slow relations between tempos to solve the baseline discrimination, the relational transfer would be easy to learn and the nonrelational transfer would be difficult, because the same fast-slow stimulus relations were associated with the same right and left keys. However, if the starlings associated an absolute tempo with a given key in the baseline discrimination, the nonrelational transfer would be easier to learn than the relational transfer, because the starlings would only have to learn one new tempo-key association-that involving the one new tempo in the transfer. A relational transfer would be difficult for the starlings using an absolute strategy, because they would have to learn two new tempo-key associations. Each of the transfer tempos was associated with a new key in the transfer. Furthermore, one of the new associations incorporated a tempo-key reversal.

Except for the foregoing changes, the procedures were identical to those used in the initial baseline training. The starlings continued with the reinforced transfer sessions for 10 days. They then returned to the original baseline discriminations for 5 days.

\section{Results and Discussion}

From the start of the first transfer session, the starlings undergoing relational transfers performed significantly better than those undergoing nonrelational transfers.

The results of the relational and nonrelational transfers are shown in Figure 4. Because inspection of the data revealed no suggestion that the starlings that were transferred from the $4 / 8$ to the $8 / 16$ stimulus set performed differently from those transferred from the $8 / 16$ to the $4 / 8$ stimulus set, and because $n$ s were small, these data were combined in the figure and in the statistical analyses. In the first transfer session, the starlings in the relational transfer were more accurate than those in the nonrelational transfer $[F(1,8)=34.8, p<.01]$. Discrimination accuracy for both groups decreased from the last day of baseline discrimination to the first day of transfer. However, for relational transfers, mean performance on the first transfer day ( $63 \%$ correct) was significantly above chance [ $50 \%$ correct, $t(4)=5.05, p<.05]$, and performance stayed above chance for the remaining transfer sessions. For nonrelational transfers, the birds' mean performance ( $41 \%$ correct) was significantly below chance on the first day $[t(3)=3.42, p<.05]$. For the nonrelational transfer, performance improved steadily such that there was no difference between the groups at the end of transfer. There were no reliable differences between the groups upon return to baseline $(p>.05)$.

It is possible that the relatively good performance in the relational group was due to rapid learning in the transfer period and not to immediate transfer of the relational discrimination. In fact, accurate discrimination in the relational condition was evident from the outset of transfer. Performance was examined on the first 10 trials and the first 50 trials for the first transfer session. The relevant data appear in Figure 5. All the starlings in the relational condition were at or above chance on both the first 10 trials and the first 50 trials $[t(4)=2.50$ and $4.45, p<$ .05 , respectively]. These data parallel quite well the data

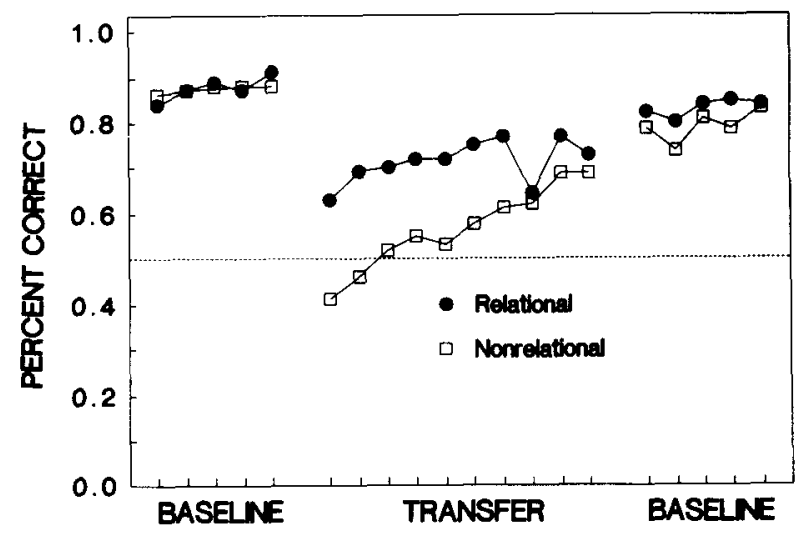

Figure 4. Mean percent correct for relational and nonrelational transfers. Data are shown for baseline sessions on the original tempo discrimination prior to the transfer, for transfer sessions, and for the return to baseline tempos following the transfer.

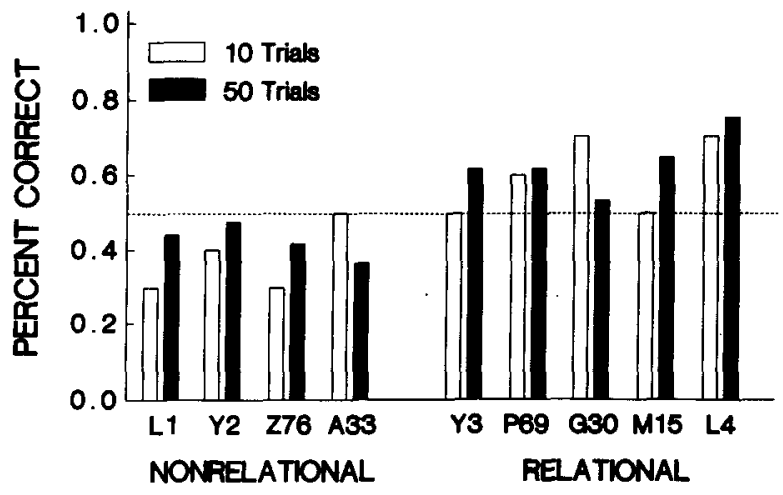

Figure 5. Percent correct for relational and nonrelational transfers on the first $\mathbf{1 0}$ and first $\mathbf{5 0}$ trials of the first transfer session for each bird. 
for the entire first day, and for the entire 10 transfer sessions (Figure 4). On the other hand, all the starlings in the nonrelational condition were at or below chance $(50 \%)$ through the first 10 trials of transfer $[t(3)=3.53, p<$ $.05]$ and 3 of the 4 starlings remained below chance through the first 50 trials $[t(2)=4.77, p<.05]$. The fourth starling (A33) in the nonrelational condition failed to complete $\mathbf{5 0}$ trials during the first session.

In sum, the starlings transferred the tempo discrimination relationally. Above-chance performance following the relational transfers was virtually immediate, significantly so within the first 10 trials of the first day. Although the starlings in the nonrelational transfer condition eventually reached substantial above-chance performance at the end of the 10-session transfer period, their initial performance was equal to or significantly below chance.

\section{GENERAL DISCUSSION}

Starlings readily discriminate between repeating patterns of tones that vary in rate or tempo. Furthermore, from a psychophysical viewpoint, starlings process these patterns much as if they are drawn from an acoustic dimension that is identical to other prothetic sensory dimensions (Stevens, 1957). Thus, probe tempos that are intermediate between two standard tempos yield a typical psychometric function, and psychometric functions show superposition for pairs of standard tempos that are multiples of one another. These psychophysical data for tempos are compatible with the propositions of scalar theories of timing for isolated intervals (e.g., Gibbon, 1977; Gibbon, Church, \& Meck, 1984). They are also compatible with the proposition that starlings respond relationally to tempo as they compare points along a tempo dimension. That is, they process pairs of tempos on a "faster than" or "slower than" basis instead of on an absolute basis, such as remembering particular absolute pulse rates.

When baseline tempos were doubled or halved in the relational and nonrelational transfers in Experiment 2, the starlings managed the relational transfer more readily than the nonrelational transfer. They found that a strategy that maintained, for example, the tempo-response-key association "slow on the left, fast on the right" was easier to follow than an absolute, nonrelational strategy that followed the absolute association "new tempo on the left, same old tempo on the right" (see Figure 2). Even though the nonrelational transfer required fewer new adjustments between a given tempo and its associated response, the starlings nevertheless opted for a relational strategy that called not only for new tempo-response-key associations, but also for a change in the association between an old tempo and the response key.

Once again, these transfer data for tempos are analogous to other data on the transfer of relative time durations for rats (e.g., Church \& Deluty, 1977) and pigeons (e.g., Dreyfus et al., 1988; Fetterman, 1987; Fetterman et al., 1986). In general, when rats and pigeons are given trans- fers of a discrimination based on long and short time intervals, they tend to respond on the basis of relations between the intervals; for example, "longer than." Our new data also agree with those of Hulse, Humpal, and Cynx (1984), which showed that starlings successfully transferred a discrimination between temporally regular and random patterns of repeating acoustic stimuli across changes in tempo. The starlings maintained the discrimination when the patterns were speeded or slowed-a relational transposition.

One caveat is in order. Although we have chosen to relational standpoint, other theories could, without too much difficulty, explain the transfer data for tempo in Figures 4 and 5 quite well. A theory based on the gradual accrual of absolute amounts of excitation and inhibition to the $S+$ and $S$ - stimuli, such as that of Spence (1940), could no doubt do the job without much difficulty. That theory, and others like it, would run into difficulty, however, if stress were added to certain pulses in a repeating pulse train to generate meter and rhythm. As we shall note briefly below, the temporal hierarchies of stress that produce meter and rhythm depend fundamentally on the perception of invariant relations among temporal events (Hulse, Takeuchi, \& Braaten, 1993). An analysis of that process with an absolute approach would be extraordinarily complex, if possible at all.

Taken together, the functional properties of individual time durations and tempos are so similar, it is natural to speculate whether and to what extent they are based on a common mechanism. What does regular repetition of an event to create a tempo require of a timing mechanism that is not also required for the isolated event itself? Perhaps the repeated constant intervals needed to manufacture a pulsed stimulus at a constant rate merely serve to reinforce the percept of the constant interpulse interval that is characteristic of the rate. In effect, the subject simply integrates or averages successive interpulse intervals to arrive at the ultimate percept of a given tempo. This process should depend on the rate with which information about the interpulse interval is obtained, and that is a function of the tempo. On the other hand, pulse for pulse, does the subject gain the same information about interpulse intervals in fast and slow tempos? Might there be some interaction between pulse rate and interpulse duration (and, for that matter, pulse duration) in establishing the percept for a given tempo? How might these events for tempo interact with perception for metrical structures, in which tempos are regularly marked at another hierarchical level by accents (Deutsch \& Feroe, 1981; Palmer \& Krumhansl, 1990; Povel \& Essens, 1985)? These questions clearly invite further comparative research.

In any case, the present data for time and tempo contrast sharply with data from transfers of serial pitch relationships by songbirds such as starlings, cowbirds, and mockingbirds (Cynx, Hulse, \& Polyzois, 1986; Hulse \& Cynx, 1985; Hulse, Cynx, \& Humpal, 1984), and by Cebus monkeys (D'Amato, 1988). In these experiments, the an- 
imals failed to make relational transfers on the basis of constant shifts in pitch ratios. For example, Hulse, Cynx, and Humpal (1984) trained starlings to discriminate pitch contours, such as four-tone rising versus falling pitch sequences. The starlings utterly failed to generalize the discrimination when the frequencies of the baseline stimuli were doubled or halved-the frequency range constraint (Cynx et al., 1986). This experiment is noteworthy because the ratio transfers of pitch are directly analogous to those of the present experiment, in which tempos were either doubled or halved. More recent research has shown that the frequency range constraint holds for stimuli drawn from virtually the entire frequency range, to which starlings are sensitive (Hulse, Page, \& Braaten, 1990).

Both the present data for tempo and earlier results for time intervals are more in line with data from another auditory dimension-loudness. In an experiment directly analogous in design to those on tempo and pitch discussed here, Bernard and Hulse (1992) showed that starlings readily transfer a discrimination based on increasing and decreasing loudness levels of a $2000-\mathrm{Hz}$ tone from one range of loudness levels to another. Apparently, compared with temporal and loudness dimensions, there is something unique about songbirds' and other animals' perceptions of serial pitch patterns.

Finally, the possibility that human and nonhuman animals appear to process repeating temporal structures on a relational basis is potentially important for the empirical and theoretical insights that might be gained about auditory concepts and principles of auditory object formation (Bregman, 1990). Humans clearly perceive metric and rhythmic structures relationally, as such structures are expressed in music (Hulse et al., 1993). The perceived patterns of intervals and temporal accents that determine the rhythmic structure of a piece of music are independent, within broad limits, of the tempo with which the music is played. Thus, music is perceptually invariant over tempo transformations. This is a good example of the relational constancies that are so characteristic of human music perception. The issue is whether the same perceptual constancies might extend to nonhuman species. If so, there may be principles of auditory perception of broad generality. The present results suggest that, at least for the perception of time and tempo, human and nonhuman animals are much alike.

\section{REFERENCES}

Bernard, D. J., \& Hulse, S. H. (1992). Transfer of serial stimulus relations by European starlings (Sturnus vulgaris): Loudness. Journal of Experimental Psychology: Animal Behavior Processes, 18, 323-334.

Bregman, A. S. (1990). Auditory scene analysis: Perceptual organization of sound. Cambridge, MA: MIT Press.

Church, R. M. (1978). The intemal clock. In S. Hulse, H. Fowler, \& W. K. Honig (Eds.), Cognitive processes in animal behavior (pp. 277-310). Hillsdale, NJ: Erlbaum.

Church, R. M., \& Broadbent, H. A. (1990). Alternative representations of time, number, and rate. Cognition, 37, 55-81.
Church, R. M., \& Deluty, M. Z. (1977). Bisection of temporal intervals. Joumal of Experimental Psychology: Animal Behavior Processes. 3, 216-227.

Cynx, J., Hulse, S. H. \& Polyzors, S. (1986). A psychophysical measure of pitch discrimination loss resulting from a frequency range constraint in European starlings (Siurnus vulgaris). Joumal of Experimental Psychology: Animal Behavior Processes, 12, 394-402.

D'Amato, M. R. (1988). A search for tonal pattem perception in Cebus monkeys: Why monkeys can't hum a tune. Music Perception. 5. 453-480.

DeursCH, D. (ED.) (1982). The psychology of music. New York: Academic Press.

Deutsch, D. , Feroe, J. (1981). The internal representation of pitch sequences in tonal music. Psychological Review, 88, 503-522.

Dooung, R. J. (1980). Behavior and psychophysics of hearing in birds. In A. N. Popper \& R. R. Fay (Eds.), Comparative studies of hear. ing in vertebrates (pp. 261-288). New York: Springer-Verlag.

Dreyfus, L. R., Fetterman, J. G., Smith, L. D., \& Stubbs, D. A (1988). Discrimination of temporal relations by pigeons. Journal of Experimental Psychology: Animal Behavior Processes, 14, 349-367.

Fetterman, J. G. (1987). Same-different comparison of duration. Animal Learning \& Behavior, 15, 403-411.

Fetterman, J. G., \& Dreyfus, L. R. (1987). Duration comparison and the perception of time. In M. L. Commons, J. E. Mazur, J. A. Nevin, \& H. Rachlin (Eds.), Quantitative analyses of behavior: Vol. 5. The effects of delay and intervening events on reinforcement value (pp. 3-27). Hillsdale, NJ: Erlbaum.

Fetterman, J. G., \&illeen, P. R. (in press). Time discrimination in Columbia livia and Homo sapiens. Joumal of Experimental Psychology: Animal Behavior Processes.

Fetterman, J. G., Stubes, D. A., Dreyfus, L. R. (1986). Scaling of events spaced in time. Behavior Processes, 13, 53-68.

Fraisse, P. (1964). The psychology of time. London: Eyre \& Spottiswode.

Fraisse, P. (1978). Time and rhythm perception. In E. C. Carterette \& M. P. Friedman (Eds.), Handbook of perception (Vol. 8, pp. 203. 254). New York: Academic Press.

Gibbon, J. (1977). Scalar expectancy theory and Weber's law in animal timing. Psychological Review, 84, 279-325.

GibBon, J. (1986). The structure of time: How time flies. In G. H. Bower (Ed.), The psychology of learning and motivation (pp. 105135). New York: Academic Press.

GibBon, J., \& AlLAN, L, G. (1984). Annals of the New York Academy of Sciences: Vol. 423. Timing and time perception. New York: New York Academy of Sciences

Gibbon, J., \& ChURCh, R. M. (1990). Representation of time. Cognition, 37, 23-54.

Gibbon, J., Church, R. M., Meck, W. H. (1984). Scalar timing in memory. In J. Gibbon \& L. Allan (Eds.), Timing and time perception (pp. 52-77). New York: New York Academy of Sciences.

GREY, J. M. (1977). Multidimensional perceptual scaling of musical timbres. Journal of the Acoustical Society of America, 61, 1270-1277.

Grey, J. M., \& Gordon, J. W. (1978). Perceptual effects of spectral modifications on musical timbres. Journal of the Acoustical Society of America, 63, 1493-1500.

Hulse, S. H., \& CYNX, J. (1985). Relative pitch perception is constrained by absolute pitch in songbirds. Joumal of Comparative Psychology. 99, 176-196.

Hulse, S. H., CrnX, J., Humpal, J. (1984). Absolute and relative pitch discrimination in serial pitch perception by birds. Joumal of Experimental Psychology: General, 113, 38-54.

Hulse, S. H., Humpal, J., \& CYNX, J. (1984). Discrimination and generalization of rhythmic and arrhythmic sound patterns by European starlings. Music Perception, 1, 442-464.

Hulse, S. H., Page, S. C., \& BraAten, R. F. (1990). Frequency range size and the frequency range constraint in auditory perception by European starlings (Sturnus vulgaris). Animal Leaming \& Behavior, 18, 238-245.

Hulse, S. H., Takeuchi, A. H., \& Braaten, R. F. (1993). Perceptual invariances in the comparative psychology of music. Music Percepiion, 10, 151-184. 
Klump, G. M., \& Maier, E. H. (1989). Gap detection in the starling (Sturnus vulgaris). Journal of Comparative Physiology, 164, 531-538.

Meck, W. H., Church, R. M., \& Olton, D. S. (1984). Hippocampus, time, and memory. Journal of Experimental Psychology: Animal Behavior Processes, 98, 3-22.

Palmer, C. , \& Krumhansl, C. L. (1990). Mental representations for musical meter. Journal of Experimental Psychology: Human Perception \& Performance, 16, 728-741.

Povel, D. J., \& Essens, P. (1985). Perception of temporal patterns. Music Perception, 2, 411-440.
SPENCE, K. W. (1940). Continuous versus noncontinuous interpretations of discrimination learning. Psychological Review, 47, 271-288. Stevens, S. S. (1957). On the psychophysical law. Psychological Review, 64, 153-181.

ZeILer, M. D. (1985). Pure timing in temporal differentiation. Journal of the Experimental Analysis of Behavior, 43, 183-193.

(Manuscript received May 25, 1991;

revision accepted for publication December 10,1992 .) 